\title{
Men without work: A global well-being and ill-being comparison
}

\section{The number of prime-age males outside the labor force is increasing worldwide, with worrying results}

Keywords: well-being, ill-being, MENA, LAC, labor force dropout, life satisfaction

\section{ELEVATOR PITCH}

The global economy is full of progress paradoxes. Improvements in technology, reducing poverty, and increasing life expectancy coexist with persistent poverty in the poorest countries and increasing inequality and unhappiness in many wealthy ones. A key driver of the latter is the decline in the status and wages of low-skilled labor, with an increasing percentage of prime-aged men (and to a lesser extent women) simply dropping out of the labor force. The trend is starkest in the US, though frustration in this same cohort is also prevalent in Europe, and it is reflected in voting patterns in both contexts.

\section{KEY FINDINGS}

\section{Pros}

๑ There are surprising differences in the well-being of prime-aged males outside the labor force across regions, with some regions experiencing less severe issues than others.

(- While training can facilitate the re-integration of younger low-skilled workers, policies to address the future of those who are no longer employable will be more challenging.

$\oplus$ Developing economies offer some potential lessons for creative solutions to enhance the productivity of those outside the labor force.

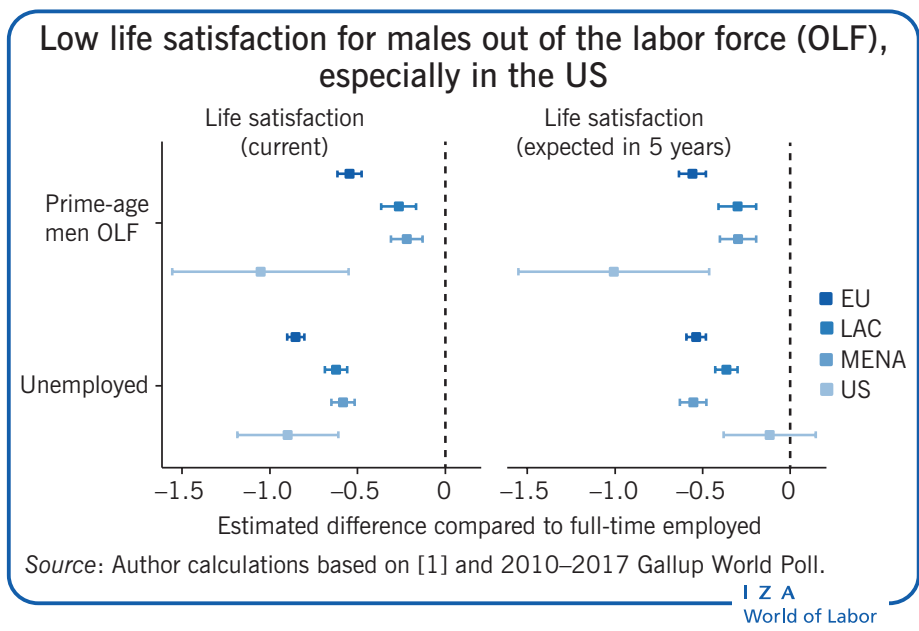

\section{Cons}

- The trend of prime-aged males dropping out of the labor force has high economic, social, and political costs, particularly in rich countries.

- The trend of prime-aged males dropping out of the labor force is likely to be exacerbated in the future, creating increased burdens for social insurance systems.

\section{AUTHOR'S MAIN MESSAGE}

The global economy is experiencing increasing numbers of workers dropping out of the labor force, particularly primeaged males in rich countries. This particularly troubled group displays high levels of desperation, stress, and anger. While more research is needed when it comes to encouraging participation by low-skilled workers, older workers can benefit from programs that reduce isolation via new opportunities for community involvement and volunteerism and improving safety nets. Better understanding the ill-being of these cohorts is a first step in addressing future labor force participation challenges. 


\section{MOTIVATION}

Despite the US being one of the wealthiest economies in the world, mortality rates are going up, driven by suicides and drug and alcohol overdoses-the so-called "deaths of despair" [2]. This trend is primarily, although not only, driven by less-than-college-educated whites in their middleaged years [3]. Poor whites report much less hope for the future and more stress than do poor African-Americans and Hispanics, even though the latter face higher objective disadvantages. Trends in ill-being-especially lack of hope-match those in premature death for individuals across different geographies [4]. Males outside the labor force (OLF) are also disproportionately represented among opioid users and on disability rolls [5]. In addition, marriage rates and civic or religious participation have fallen more for the working class-in part related to labor force dropout-since the 1970s [6]. Another factor in this ill-being is the strong norm of hard work and individual effort, and the stigma associated with not working [7]. Perhaps unsurprisingly, such men are also more likely to live in counties that voted for Donald Trump in 2016 [8].

Unlike the US and the EU, many countries in the Middle East and North Africa (MENA) have a long history of under- and unemployment among prime-aged males (aged 25-54). At the time of the 2011 Arab Spring uprisings much research focused on frustration among this group as a possible cause of the discontent, but with inconclusive results. In the countries where uprisings took place, there is little evidence of either the middle class or youth being particularly dissatisfied by comparison with other groups in the same countries [9]. Earlier research attempted to compare MENA countries where uprisings did and did not take place and found no systematic differences in life satisfaction trends [10]. Moreover, despite the public frustration, most of the countries where uprisings took place were experiencing positive levels of economic growth. This is suggestive of the "progress paradox" phenomenon-in which significant segments of the population are left behind-which has been found in other countries and regions around the world, including those referenced above [2]. Recent research finds that prime-aged males OLF in MENA are not particularly unhappy compared to the fulltime employed, and have significantly higher levels of well-being than the unemployed [1].

\section{DISCUSSION OF PROS AND CONS}

\section{Prime-aged males OLF are distinct from the unemployed within and across regions}

Understanding the drivers of the trends of prime-aged males OLF is a first step toward resolving them. While this cohort differs in many ways across countries and regions, it is notable that this group is not at the very bottom of the income distribution in all regions [1]. While their income levels are typically below their country averages, they are similar to or even slightly higher than those of the unemployed. In the developing regions of Latin America and the Caribbean (LAC) and MENA, individuals who report being out of the labor force may be working in the informal sector.

In the US, the average incomes of OLF males are around the same level as the unemployed and roughly cross the bottom two income quintiles. Yet there is high variance, with outliers at both the bottom and top ends of the distribution. The poorest benefit more from safety nets such as food stamps and Medicaid-and/or the wages of a spouse or parent-while those near the working class, defined as being between the 20th and 50th percentile of household income, benefit proportionately more from disability insurance, which is a lifelong benefit [6], [11]. The composition of this group also extends beyond blue-collar whites [12], although blue-collar whites are both disproportionately represented in recent OLF trends and are the cohort with the lowest levels of well-being. In the EU and within the OLF, there is less variance in pre-tax income, which is likely further mitigated by widely available and generous welfare programs. 


\section{Causes for and differences in dropping out of the labor force}

There are more differences in the traits of those who have dropped out of the labor force across the regions. Prime-aged males in the US who have dropped out of the labor force stand to benefit from either re-training programs for those who are young and willing to participate or from community-based programs to reduce social isolation and desperation, as well as from broader safety nets. In contrast, those in developing regions such as LAC and MENA could benefit from labor market reforms that reduce the barriers between the formal and informal sectors. In these latter regions, the "formally" unemployed are a small part of the working population, compared to the informally employed.

Despite its reputation for having flexible labor markets, the US has one of the lowest primeage male labor participation rates in the OECD, and one that has been on a downward trend since 1999 [11]. The reasons for labor force dropout in the US have remained fairly consistent: $30 \%$ of the OLF are ill or disabled, $40 \%$ are caregivers, $8 \%$ are students, and $5 \%$ are early retirees. The majority of them have a high school degree or less and they cross all racial cohorts. In contrast to prime-age women OLF, OLF males are more likely to be living with a parent, and only a small part of this group has a working spouse. Reliance on disability insurance (SSDI), while often cited as an explanation, is not the whole story: coverage of SSDI has increased by $2 \%$ since 1967 , while participation has declined by $7 \%$. The institutional structures in the US likely contribute to its high dropout rate as low-skilled labor has little collective bargaining power compared to other OECD countries, and there has been an increase in low-quality unstable jobs with few if any benefits, which is in turn reflected in a trend of median wages relatively decreasing for this group [13].

Automation and skill-biased technological change pose additional challenges to the labor force participation of lower-skilled workers. There are no magic bullets for dealing with growth that is increasingly driven by these factors, which is likely to continue displacing lowskilled workers. Re-thinking the future of work in the global economy will have to include creative policies for retraining and/or additional support to these workers. Given the younger demographic profiles of LAC and MENA, such policies might be particularly productive for preparing at least some of the next generation in these regions. Lessons from well-being research on interventions that reduce the isolation of older workers who are unlikely to become re-employed in the advanced economies can mitigate their ill-being. Failure to do so could exacerbate the already high social and political costs seen in advanced economies.

\section{The subjective well-being of prime-aged males OLF compared to other employment groups}

The broader literature reports many trends suggesting that prime-aged males OLF are a worrisome group, not just in terms of employment status, but also in terms of income, health, and family stability, particularly in the US, but also in Europe [4], [5], [6], [7], [8]. III-being markers range from poor objective health status to high levels of reported pain medication and opioid dependence to excessive amounts of time spent in isolation. Recent research tries to complement these markers with some insights from subjective well-being data based on the Gallup World Poll to explore how prime-aged males OLF compared to other labor market cohorts across several regions of the world [1].

This recent work focuses on two main well-being dimensions. "Evaluative well-being" seeks to capture how individuals currently assess their own lives and their expectations for the future, in this instance assessed on a $0-10$ scale. "Hedonic well-being" aims to capture individuals' moods and how they experience their daily lives; it assesses negative and positive affects separately (as they are separate constructs that cannot be measure on one scale), including 
stress, worry, and anger on the one hand, as well as experiencing enjoyment, smiling, or being treated with respect on the other. These are all assessed with respect to the previous day and are binary indicators.

The figures produced for this study illustrate the well-being situation of several groups, based on their labor market status [1]. The illustration on p. 1 focuses on evaluative well-being, as measured by current life satisfaction and life satisfaction expected in five years. For each indicator, it displays the coefficient estimates for prime-age males OLF and for unemployed respondents in each region-the reference category corresponds to the "full-time employed" in each respondent's region. Those estimates come from regressions that account for a range of socio-economic and demographic controls (along with country and year fixed effects). Therefore, the illustration allows only for relative comparisons of different labor market statuses within each region. It shows the gaps in current life satisfaction and life satisfaction expected in five years between prime-age males OLF and full-time employed respondents in the top panel, and between unemployed and full-time employed respondents in the bottom panel.

Within all regions prime-age males OLF have significantly lower current and future life satisfaction relative to the full-time employed. Although not displayed in the illustration, they also have lower life satisfaction (current and future) than other OLF groups, such as primeage females or youth and elderly of either gender. Relative to other labor market statuses, this cohort is especially dissatisfied and pessimistic within the US. On the other hand, the life satisfaction gap between prime-age males OLF and the full-time employed is the smallest in MENA.

It is also worth noting that, in general, those who are unemployed typically score as low or lower than prime-aged males OLF. The main exception is the US, where the latter are both very unhappy and very pessimistic, even compared to the unemployed.

In MENA and LAC, both groups have narrower current and future life satisfaction gaps compared to the full-time employed than do their counterparts in the US and EU. This may be due to the lower levels of stigma associated with being informally employed in developing countries. It may also be that individuals in more deprived contexts emphasize hope for the future in the absence of capacity to control their lives, as the existing literature suggests [2]. The higher levels of optimism found among poor US minorities, compared to poor whites, also resonates here [4].

Figure 1 illustrates the direct evaluative well-being comparison of only prime-age males OLF across regions. It displays the coefficient estimates for LAC, MENA, and US respondents, with the EU as reference category. This figure paints a more complex picture. While the illustration on p. 1 reveals that MENA is the region with the smallest differences in life satisfaction between prime-age males OLF and those who have full-time employment, Figure 1 shows that, in absolute terms, prime-age males OLF-and the full-time employed-in MENA are the least satisfied across the four regions. This is likely due to the overall lower levels of life satisfaction for all respondents in MENA compared to the three other regions (and the consistently high levels of subjective well-being in LAC compared to other regions of comparable income levels).

Prime-age males OLF also have more negative and less positive affect, relative to the reference group of the full-time employed, within all regions (Figure 2). As with the evaluative indicators, they tend to score higher in ill-being and lower on well-being markers than other OLF groups.

When compared to the full-time employed, prime-age males OLF in MENA again fare comparatively well. The differences between the two groups are consistently among the 
Figure 1. Evaluative well-being for prime-age males OLF (across region comparisons)

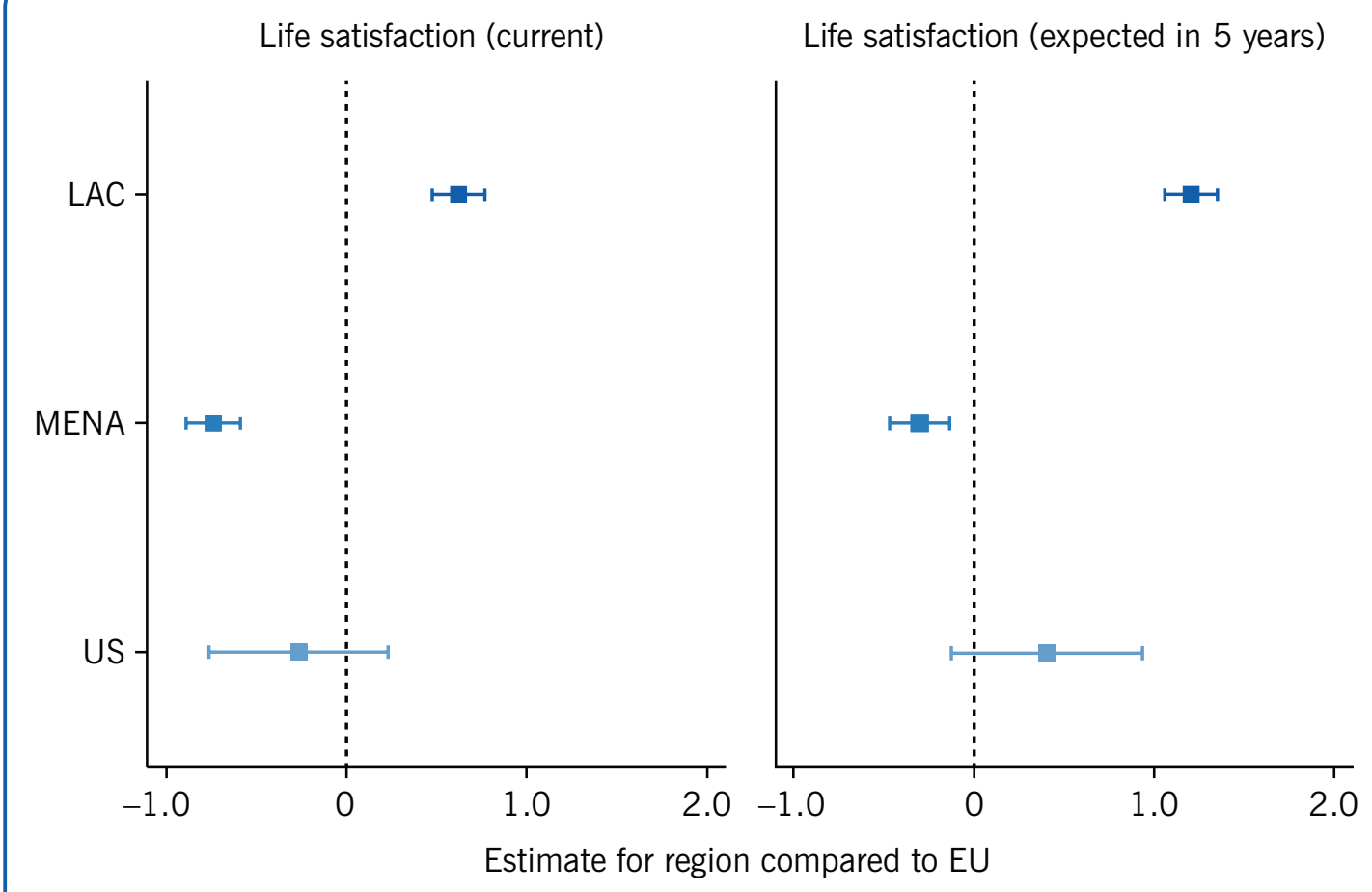

Note: Evaluative well-being is measured on a 0-10 scale. Estimates are based on regressions that control for age, gender, marital status, education, living in a rural area, being native-born, importance of religion, log of household income, household size, as well as year fixed effects. Bars represent $95 \%$ confidence intervals. Vertical lines represent the EU as the reference region.

Source: Author calculations based on [1] and 2010-2017 Gallup World Poll.

lowest for both negative and positive affect (Figure 2). By contrast, the US cohort displays particularly high ill-being and low well-being relative to those who are employed full-time, with the gaps generally higher than in the other regions. In several of these indicators, they also score as badly or even worse than those who are unemployed-something that typically is not observed in the other regions.

Figure 3 shows the direct comparisons of prime-age males OLF across regions in negative and positive affect indicators, respectively. As in the evaluative indicators, these figures suggest an important caveat: while MENA has the smallest differences in hedonic indicators between prime-age males OLF and those who have full-time employment, in absolute terms, prime-age males OLF in MENA report low well-being and are closer to the US than to LAC in terms of levels of negative affect and the low positive affect. Again, this likely reflects the low absolute levels of well-being in MENA (and the high levels in LAC) compared to other regions.

\section{Perceptions about the economy, labor market, and mobility}

The indicators within this dimension portray a different picture than those for evaluative and hedonic well-being, as the gap between prime-age males OLF and full-time employed respondents is, if anything, larger in EU and LAC countries, particularly regarding job perceptions. In MENA, the gaps between the perceptions of prime-age males OLF and the full-time employed remain small, as with other indicators. 
Figure 2. Hedonic indicators compared to full-time employed (within-region) for the EU, MENA, LAC, and US

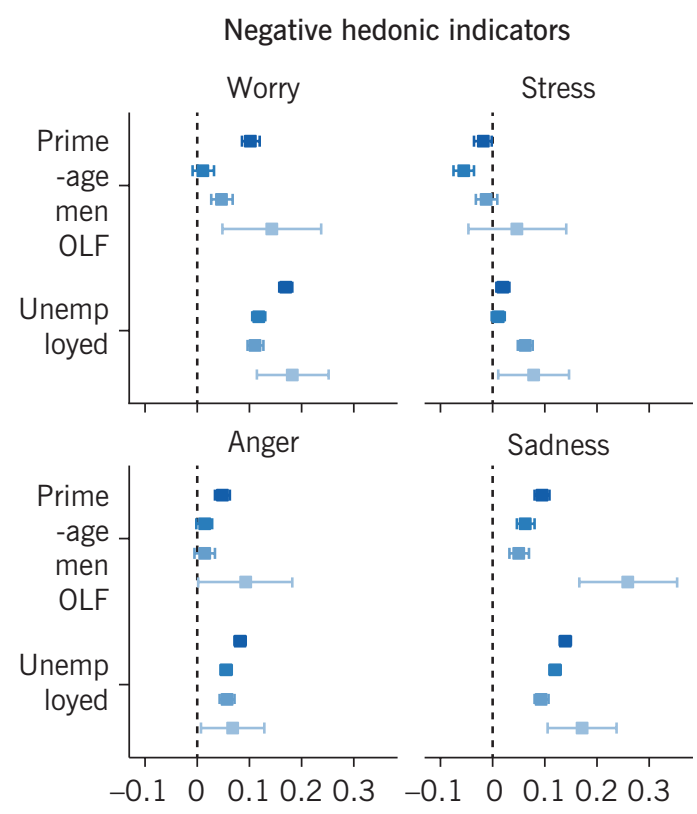

Estimated difference compared to FT employed

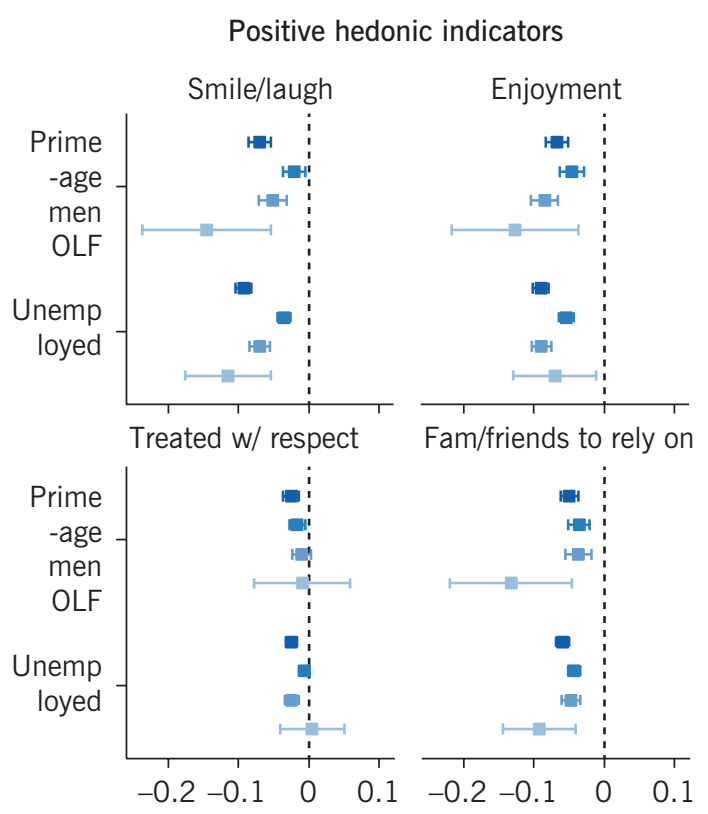

Estimated difference compared to FT employed

- EU LAC MENA US

Note: Evaluative well-being is measured on a 0-10 scale. Estimates are based on regressions that control for age, gender, marital status, education, living in a rural area, being native-born, importance of religion, log of household income, household size, as well as year fixed effects. Bars represent $95 \%$ confidence intervals. Vertical lines represent the $\mathrm{EU}$ as the reference region.

Source: Author calculations based on [1] and 2010-2017 Gallup World Poll.

Surprisingly, and contrary to the previous dimensions, the perceptions of prime-age males OLF in the US are similar to those of full-time employed respondents, and generally less negative than those of the unemployed. Even more surprisingly, prime-aged males OLF in the US are more likely to say it is a good time to find a job than both the unemployed in the US and prime-aged males OLF in the other regions. This OLF-unemployed difference also appears in the EU and MENA (perhaps due to informality in the latter). Yet, it is most surprising in the US where these reported beliefs do not accord with the objective increase in prime-age males dropping out of the labor force, suggesting that either their expectations are out of line with the kinds of jobs and wages that are available, that they cannot work due to disability or drug issues, or both.

As along most of the previous dimensions, those who are unemployed generally have, within each region, more negative perceptions and beliefs relative to prime-age males OLF-the exceptions being LAC, where there is little difference between both groups. In MENA, the unemployed are a subset of a small (and relatively privileged) formal sector labor market, and, as such, likely have unmet expectations.

\section{LIMITATIONS AND GAPS}

Research on labor force dropout by prime-aged men in advanced economies is in its early stage. Standard economic tools partially explain this trend. Yet there is more to the story. Some of the relevant research relies on well-being metrics to compare the well-being-and 
Figure 3. Hedonic indicators for prime-age males OLF (across region comparisons)
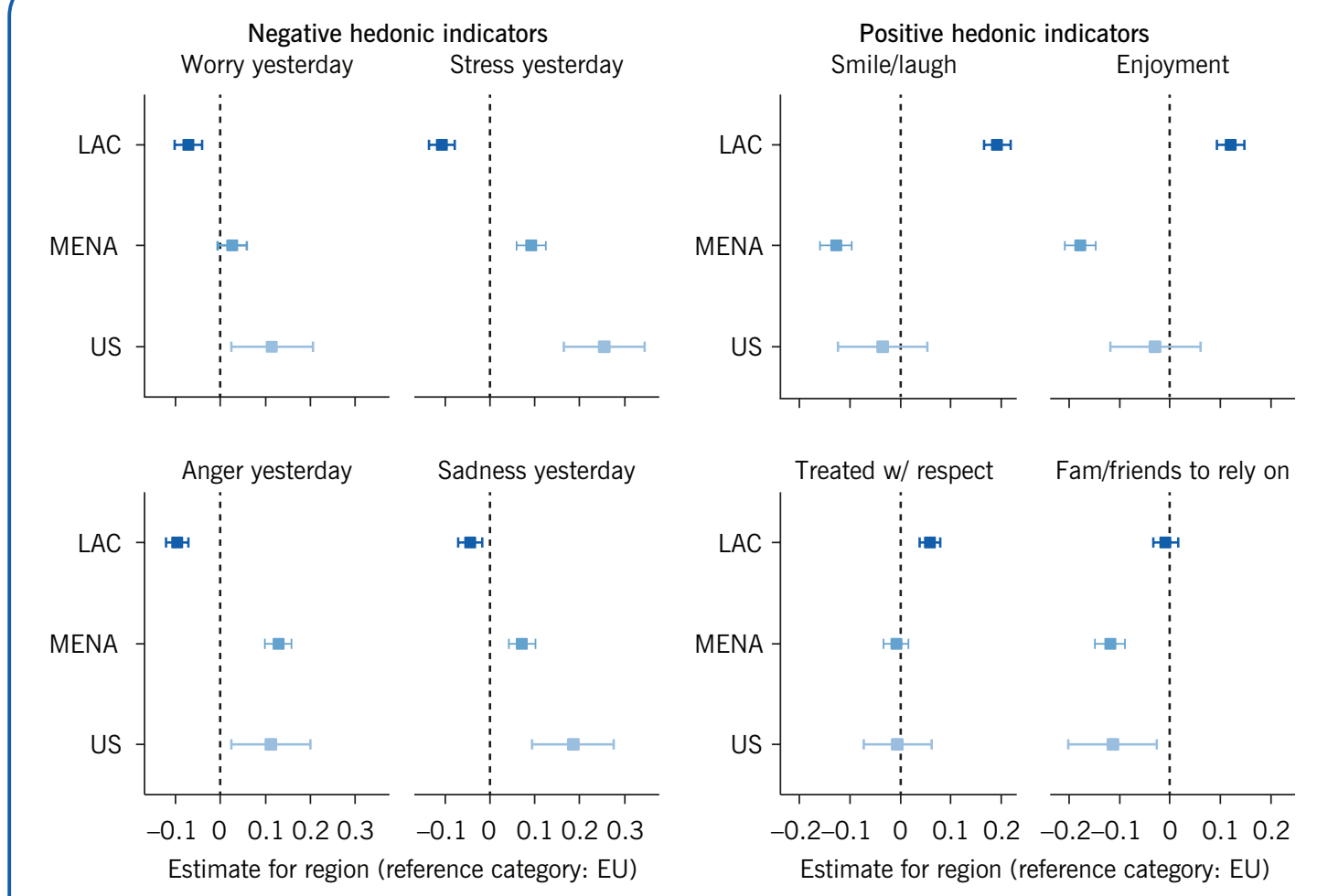

Note: Evaluative well-being is measured on a $0-10$ scale. Estimates are based on regressions that control for age, gender, marital status, education, living in a rural area, being native-born, importance of religion, log of household income, household size, as well as year fixed effects. Bars represent $95 \%$ confidence intervals. Vertical lines represent the $\mathrm{EU}$ as the reference region.

Source: Author calculations based on [1] and 2010-2017 Gallup World Poll.

ill-being-of this cohort [4], [5]. Other work relies on extensive individual or focus group interviews [7], [12]. Both approaches paint a picture of a complex story that is partially but not only explained by supply and demand factors, but also has to do with issues of identity, expectations, and social norms that vary across regional contexts.

Some of the differences in well-being across regions may be due to different labor markets and working arrangements, with those in advanced countries much more likely to be totally out of the labor force, and those in developing regions more likely to be working in the informal sector and displaying higher levels of well-being, perhaps due to the freedom and flexibility-despite the uncertainty-that comes with working in this sector. While there is potential for this sector to play a positive role in addressing current labor market changes and challenges in developing countries, there are also differences in the productivity and quality of informal sector jobs within and across countries, making it difficult to generalize.

While the different studies provide important insights, given the paucity of large-scale panel data, it is not possible to determine the causal effect of labor force dropout on well-being. It may be that this group had initially low levels of well-being and resilience that precipitated their labor force dropout, rather than the other way around. Earlier work suggesting that individuals with higher levels of well-being have better future labor market and health outcomes suggests this is plausible [14]. This is a broader question that must be addressed in future research, as the answer will be a critical part of the solution to the increasing problem of prime-aged workers dropping out of the labor force. 


\section{SUMMARY AND POLICY ADVICE}

Prime-age males OLF in the US typically have the largest well-being gaps relative to those who work full-time, and in several instances even compared to the unemployed. The strong individual work ethic and lack of support for collective safety nets that characterizes the American dream contributes to the strong stigma of being out of the labor force in the US, in contrast with more broadly shared support for collective safety nets in the EU. When directly comparing the absolute levels of well-being of prime-age males OLF across regions, those in MENA (and, for the most part, also in the US) have particularly low levels. This suggests that in MENA, while there are relatively small differences in well-being between prime-age males OLF and those employed full-time, both groups have low well-being levels to begin with.

Yet there is less consistency-and data-on the state of these cohorts in other regions, and particularly in MENA. Despite much discussion suggesting that poor life satisfaction among under- or unemployed men in MENA was a possible catalyst for the Arab Spring uprisings, they are not particularly dissatisfied compared to those employed full-time, relative to what is observable within other regions. This may have something to do with the longer trajectory and social acceptance of male under- and unemployment in MENA (and to a lesser extent in $L A C$ ), compared to the US and the EU, where it is a relatively novel phenomenon.

The high rate of labor force dropout in the US meanwhile, is in large part explained by poor objective conditions for low-skilled labor, in contrast to the generous safety nets which characterize the EU economies.

It is important to note that the relatively newer trend of labor force dropout in the US comes with high levels of stigma. Less-than-college-educated white males, a group for whom the increases in labor force dropout have been stark, are also particularly vulnerable to premature mortality due to suicide, and opioid and other drug overdoses. These same trends in preventable deaths also match ill-being patterns and contrast with more resilience among minorities, who have had to deal with unstable and inferior jobs for a much longer period of time [4]. Standard social structures, such as marriages and community participation, have also eroded for the OLF in the US, more so than in other regions.

The same labor market problems-and associated challenges-that have existed for decades in MENA show little signs of abating. While informal labor markets are widespread, they are also unlikely to solve broader employment challenges going forward, particularly if there is increased technology-based displacement. Indeed, all regions will continue to face the same or even greater challenges in an era of technology-driven growth, which in turn raises questions about current growth models and measures of progress.

Much more knowledge is needed about the kinds of policies that can encourage the participation of able low-skilled workers in the new global economy. These could include better incentives for working in the low-skilled sector, such as leave policies and at least some guarantees of stability or severance, which have all been eroded, particularly in the US. Such policies may require a central government role, via subsidies or regulation, as increasing firm concentration and market power have exacerbated labor's declining bargaining power.

Equally important are supply-side policies, which include vocational training for lessthan-college-educated younger workers, such as preparation for programming and other technology support jobs. For older cohorts, for whom re-training is difficult, wellbeing research provides examples of programs that enhance well-being and reduce social isolation via new opportunities to volunteer, participate in the arts, and be involved in other community-level activities. 


\section{Acknowledgments}

The authors thank an anonymous referee and the IZA World of Labor editors for many helpful suggestions on earlier drafts.

\section{Competing interests}

The IZA World of Labor project is committed to the IZA Code of Conduct. The authors declare to have observed the principles outlined in the code.

(C) Carol Graham and Sergio Pinto 


\section{REFERENCES}

\section{Further reading}

Naidu, S., E. Posner, and G. Weyl. "Antitrust remedies for labor market power." Harvard Law Review 132:536 (2018).

Stone, A., and C. Mackie. Subjective Well-Being: Measuring Happiness, Suffering, and Other Dimensions of Human Experience. Washington, DC: National Academies Press, 2013.

\section{Key references}

[1] Pinto, S., and C. Graham. Men without Work: Why They are so Unhappy in the US Compared to Other Places. Brookings Institution Global Economy and Development Working Papers No. 128, 2019.

[2] Graham, C., K. Laffan, and S. Pinto. "Well-being in metrics and policy." Science 362:6412 (2018): 287-288.

[3] Case, A., and A. Deaton. "Mortality and morbidity in the 21st century." Brookings Papers on Economic Activity (2017): 397-452.

[4] Graham, C., and S. Pinto. "Unequal hopes and lives in the USA: Optimism, race, place, and premature mortality." Journal of Population Economics 32:2 (2019): 665-733.

[5] Krueger, A. "Where have all the workers gone? An inquiry into the decline of the US labor force participation rate." Brookings Papers on Economic Activity (2017).

[6] Opportunity America, American Enterprise Institute, and the Brookings Institution. Work, Skills, Community: Restoring Opportunity for the Working Class. Washington, DC: Opportunity America, American Enterprise Institute, and the Brookings Institution, 2018.

[7] Sawhill, I. The Forgotten Americans: An Economic Agenda for a Divided Nation. New Haven: Yale University Press, 2018.

[8] Monnat, S., and D. Brown. "More than a rural revolt: Landscapes of despair and the 2016 presidential election." Journal of Rural Studies 55 (2017): 227-236.

[9] Cammett, M., and N. Salti. "Popular grievances in the Arab region: Evaluating explanations for discontent in the lead-up to the uprisings." Middle East Development Journal 10:1 (2018): 64-96.

[10] Graham, C., S. Chattopadhyay, and M. Amin. After the Spring: Economic Transitions in the Arab World. Oxford: Oxford University Press, 2012.

[11] Schanzenbach, D. W., L. Bauer, R. Nunn, and M. Mumford. "Who is out of the labor force?" Economic Analysis (2017).

[12] Yarrow, A. Man Out: Men on the Sidelines of Life in America. Washington, DC: Brookings Institution Press, 2018.

[13] Office of the President of the United States. The Long Term Decline in Prime Age Male Labor Force Participation. Washington, DC: Council of Economic Advisors, 2016.

[14] Graham, C., A. Eggers, and S. Sukhtankar. "Does happiness pay? Some insights from happiness data for Russia." Journal of Economic Behavior and Organization 55:3 (2004) : 319-342.

\section{Online extras}

The full reference list for this article is available from:

https://wol.iza.org/articles/men-without-work-a-global-well-being-and-ill-being-comparison

View the evidence map for this article:

https://wol.iza.org/articles/men-without-work-a-global-well-being-and-ill-being-comparison/map 